\title{
Ductal Carcinoma
}

\author{
Narges Takhshid ${ }^{1}$ and Hossein Fahimi (iD) ${ }^{1, *}$ \\ ${ }^{1}$ Department of Genetics, Faculty of Sciences, Science and Research Branch, Islamic Azad University, Tehran, Iran \\ "Corresponding author: Department of Genetics, Faculty of Sciences, Science and Research Branch, Islamic Azad University, Tehran, Iran. Email: h.fahimi@iaups.ac.ir
}

Received 2021 July 09; Accepted 2021 August 16.

\begin{abstract}
Background: Breast cancer is one of the most common cancers worldwide and is responsible for the death of many people. It is mainly found in women; however, it is rarely observed in men. Nowadays, extensive research has been conducted on the detection, diagnosis, and prognosis of biomarkers of this type of cancer, as well as other types. MicroRNAs play a major role in regulating the onset and progression of breast cancer. To date, many significant increases and decreases in microRNAs levels have been reported during various cancers, and also tumor inhibitory roles have been reported for these small non-coding RNA molecules.

Methods: In this study, miR-30a and miR-200c were studied to find new expression patterns in breast cancer patients. For this purpose, a quantitative polymerase chain reaction was used to analyze the relationships between expression levels of miR-30a and miR-200c and several clinical and pathological features of the disease, such as tumor stage, HER2 gene expression, and lymphatic metastasis.

Results: Our results showed that the expression of miR-200c and miR-30a in tumor samples was significantly lower than in normal samples $(\mathrm{P}<0.01)$. Also, at higher stages of the disease, the expression of both miRNAs was remarkably reduced $(\mathrm{P}<0.01)$. We also found that the expression of two miRNAs in patients with HER2 gene expression and metastasis in lymphatic regions was significantly lower than in HER2-negative and non-metastatic patients $(\mathrm{P}<0.05$ and $\mathrm{P}<0.01$, respectively).

Conclusions: We identified the relationship between miR-200c and miR-30a and breast cancer. These findings indicate that these microRNAs can be considered biomarkers in breast cancer.
\end{abstract}

Keywords: Breast Ductal Carcinoma, MicroRNA, Diagnosis, Differential Expression

\section{Background}

The most common cancer among women worldwide is breast cancer (BC), which is also the fifth leading cause of cancer-related death (1). Although there have been notable recent achievements in diagnosis and treatment, $20 \%-30 \%$ of $\mathrm{BC}$ patients develop metastasis (2). One of the factors that can lead to increased cancer mortality is the metastasis of cancer cells to vital organs (3). In general, changes in the expression of some genes can stimulate metastasis in certain organs (4). Metastasis affects different sites and has different rates depending on the primary tumor subgroup (5).

BC includes almost four molecular subtypes: Luminal A, luminal B, HER2-enriched, and triple-negative (6). About $60 \%$ of all patients with BC have luminal A subtype of this disease $(7,8)$. HER2-enriched BC occurs in $15 \%-25 \%$ of patients due to increased expression of the human epidermal growth factor receptor 2 (HER2) gene and is more aggressive $(9,10)$.

Time is a crucial factor in the detection of BC; therefore, some approaches are used for timely diagnosis and prognosis. Current diagnostic and therapeutic methods have some weaknesses; thus, molecular markers can be widely used in the diagnosis of BC. Accordingly, the main candidates for early-stage biomarkers are proteins, gene expression, and microRNA expression (11).

MiRNAs are short single-stranded RNAs with 18 - 23 nucleotides and are obtained from 70 nucleotide precursors. They manage both physiological and developmental processes through gene expression, and consequently, they play a notable role in gene expression and posttranscriptional regulation (12-15).

Recent studies have shown that miRNAs are recognized as important biomarkers in many cancers (16). Further- 
more, each microRNA in humans can target hundreds of mRNAs; thus, they are able to regulate several cellular processes, like development, differentiation, and proliferation (17). Based on miRNA databases, there are more than 2500 mature microRNA sequences in the human genome (18, 19). It is estimated that more than $60 \%$ of the proteins encoding genes in humans in their 3'-UTRs have miRNA binding sites (20). MicroRNAs interpose the suppression of $\mathrm{mR}$ NAs by pairing to the complementary base sequences in 3'UTR, which causes instability in transcription or repression in translation or both (21). Some recent studies have shown that the expression of some genes is also regulated by exon-linked microRNAs (22-24).

\section{Objectives}

In the present study, the eligibility of miR-200c and miR-30a as biomarkers of BC was studied. Additionally, the relationships between expression levels of these microRNAs and tumor stage, HER2 expression, and lymphatic metastasis were also assessed.

\section{Methods}

\subsection{Patients and Specimens}

We included 30 patients with ductal carcinoma, of whom 18 cases were less than 50 years old. Also, 14 patients had never received hormone therapy, while the rest had received this therapy. (Table 1 ). The normal and tumor samples were collected from the cancer institute of Imam Khomeini Hospital Affiliated with Tehran University of Medical Sciences. Before any analysis, the subjects completed the informed consent. The samples were conserved in RNase-free tubes, put immediately in liquid nitrogen, sent to the laboratory, and stored at $-80^{\circ} \mathrm{C}$.

\subsection{RNA Extraction and Real-Time PCR}

Total RNA from the patient was isolated (Parsgenome RNA extraction kit), following the manufacturer's protocol. Next, quantitative and qualitative evaluation was performed by UV spectrophotometry (via NanoDrop ${ }^{\circledR}$ ND1000). Moreover, the miRNA cDNA was synthesized using the miRNA cDNA Synthesis kit (Parsgenome) and used as a template for a quantitative real-time PCR (qRT-PCR). Next, real-time PCR was performed on an Applied Bio-system real-time PCR instrument with microRNA and universal and specific primers. We used the U6 snRNA gene as the

\begin{tabular}{|c|c|}
\hline Characteristics & Values $^{\mathrm{a}}$ \\
\hline \multicolumn{2}{|l|}{ Age } \\
\hline$>50$ & $18(60)$ \\
\hline$\leq 50$ & $12(40)$ \\
\hline Total & $30(100)$ \\
\hline Median & $49.32(30-76)$ \\
\hline \multicolumn{2}{|l|}{ Tumor size, cm } \\
\hline$<3$ & $12(40)$ \\
\hline$\leq 3$ & $18(60)$ \\
\hline \multicolumn{2}{|c|}{ Metastasis to lymph nodes } \\
\hline Positive & $11(37)$ \\
\hline Negative & $19(63)$ \\
\hline ER & $18(60)$ \\
\hline ER+ & $9(30)$ \\
\hline ER-unknown & $3(10)$ \\
\hline \multicolumn{2}{|l|}{ HER2 status } \\
\hline Her2+ & $16(53)$ \\
\hline Her2- & $13(43)$ \\
\hline Unknown & $1(0.3)$ \\
\hline
\end{tabular}

${ }^{\mathrm{a}}$ Values are expressed as No. (\%) unless otherwise indicated.

housekeeping gene to compare target RNA expression levels. All reactions were performed in triplicate. Afterward, the data were converted to cycle threshold $(\mathrm{Ct})$, to normalize each microRNA expression ratio with $2^{-\Delta \Delta \text { CT }}$ method, where $\Delta \mathrm{Ct}=\mathrm{U6} \Delta \mathrm{Ct}-\mathrm{miRNA} \Delta \mathrm{Ct}$.

\subsection{Melting Curve Analysis}

In our study, having only one peak for each gene's melting curve showed specificity in the PCR, whereas there would have been more curves (shorter ones) if there was impurity (such as dimer primers).

3.4. Relationship between breast cancer pathogenesis and selected microRNAs

To discover the relationship between $\mathrm{BC}$ pathogenesis and selected microRNAs, we measured the miR-200c and miR-30a expression levels in tumor tissue from $\mathrm{BC}$ patients and normal tissues surrounding it ( $\mathrm{n}=30$ patients).

3.5. The Potential of miR-200c and miR-30a to be Selected as Biomarkers

To assess the miR-200c and miR-30a potential as biomarkers for diagnosing the breast tumor tissues, we an- 
alyzed the receiver operating characteristics (ROC) curve.

\subsection{Statistical Analysis}

Data were expressed as the median \pm standard deviation obtained from 2 or 3 separate experiments. The statistical data analysis was done using a $t$-test. A P-value $<0.05$ was considered to be significant.

\section{Results}

4.1. Melting Curve Analysis and Specificity of Real-Time PCR Products

Curve analysis for U6snRNA, miR-200c, and miR-30a showed only one peak for these genes at the specific melting temperature, which indicated the specificity of the PCR products (Figure 1).

4.2. The miR-200c and miR-30a Are Significantly DownRegulated in Tumor Tissues of Breast Cancer Patients

Our results showed a notably lower than normal expression level for miR-200c in tumor tissue compared to healthy tissue around the tumor. The miR-30a also had a lower expression level in $\mathrm{BC}$ patients $(\mathrm{P}<0$. 01) (Figure 2$)$.

4.3. Decreased Expression Level of miR-200c and miR-30a Is Associated with Higher Stages of Breast Cancer

To observe miR-200c and miR-30a expression levels in different stages, we divided cancer stages into two groups (stage I and II versus stage III and IV). The results indicated that miR-200c and miR-30a expression levels were lower in stages III and IV $(\mathrm{P}<0$. 01) (Figure 3 ).

4.4. The miR-200c and miR-30a Expression Levels in HER-2Positive Patients and Patients with Metastasis to Lymph Nodes

We also evaluated the expression levels of miR-200c and miR-30a in patients with lymph node metastasis compared to non-metastatic cases and also in HER-2-positive patients compared to HER-2-negative patients (Figure 4).

\subsection{The miR-200c and miR-30a Are Appropriate Biomarkers in Breast Cancer}

Our results indicated that both microRNAs showed lower expression levels in tumor tissues than normal ones. The area under the curve (AUC) indicating the potential of miR-200c and miR-30a as biomarkers was 0.90 and 0.78, respectively, which showed their high potential to be considered as biomarkers (Figure 5).

\section{Discussion}

The most common method for early detection of BC is mammography, which provides a high rate of falsepositive results. Other methods include the use of breast imaging and biopsy, which are invasive methods that affect the quality of life. The use of sensitive methods is essential for the early detection of BC (25). MicroRNAs are important regulators that play a regulatory role in many types of cancer (26). They are stable molecules in body fluids, including blood and cerebrospinal fluid; thus, they are potent biomarkers for early non-invasive detection of $\mathrm{BC}$ (27).

MiR-30a is a target molecule associated with epithelialmesenchymal transmission (EMT) that suppresses migration and invasion in some cancers, including BC (28-30). It also inhibits several important inhibitors, including Eya2, ITGB3, and UBE3C (31-34). Zeng et al. (35) showed that miR30a levels were significantly associated with estrogen receptor (ER) and triple-negative $\mathrm{BC}(\mathrm{P}=0.005$ and $\mathrm{P}=0.007$, respectively). In addition, they showed that the sensitivity and specificity of miR-30a for BC diagnosis were 74\% and $65.6 \%$, respectively (35). Kawaguchi et al. found that miR30a and miR-200c had a significant prognosis in the Cancer Genome Atlas (TCGA) data portal. Their study showed that the overexpression of these tumor suppressors, including miR-30a and mir-200c, was associated with overall survival (OS) (36). Hurteau et al. (37), for the first time in 2007, showed that miR-200c overexpression led to decreased ZEB1 gene expression and increased E-cadherin expression in BC cell lines. Also, many reports have shown that miR-200c has EMT-dependent tumor suppressor function in $\mathrm{BC}(38,39)$. The miR-200c may have a protective effect against BC, leading to an increase in the patients' survival time. Sergio et al. suggested that patients with high levels of miR-200c expression had a better prognosis and longer survival than patients with low expression levels in stage I ovarian cancer (40). Furthermore, the miR-200c expression showed a significant decrease in colon cancer. Its expression is also inversely related to tumor size, serous attack, lymph node metastasis, and tumor node metastasis (41).

The results of the present study are in line with previous studies demonstrating that the miR-200c expression as a tumor suppressor is decreased in BC compared to normal tissues; thus, these microRNAs play an important role in metastasis and invasive BCs. 

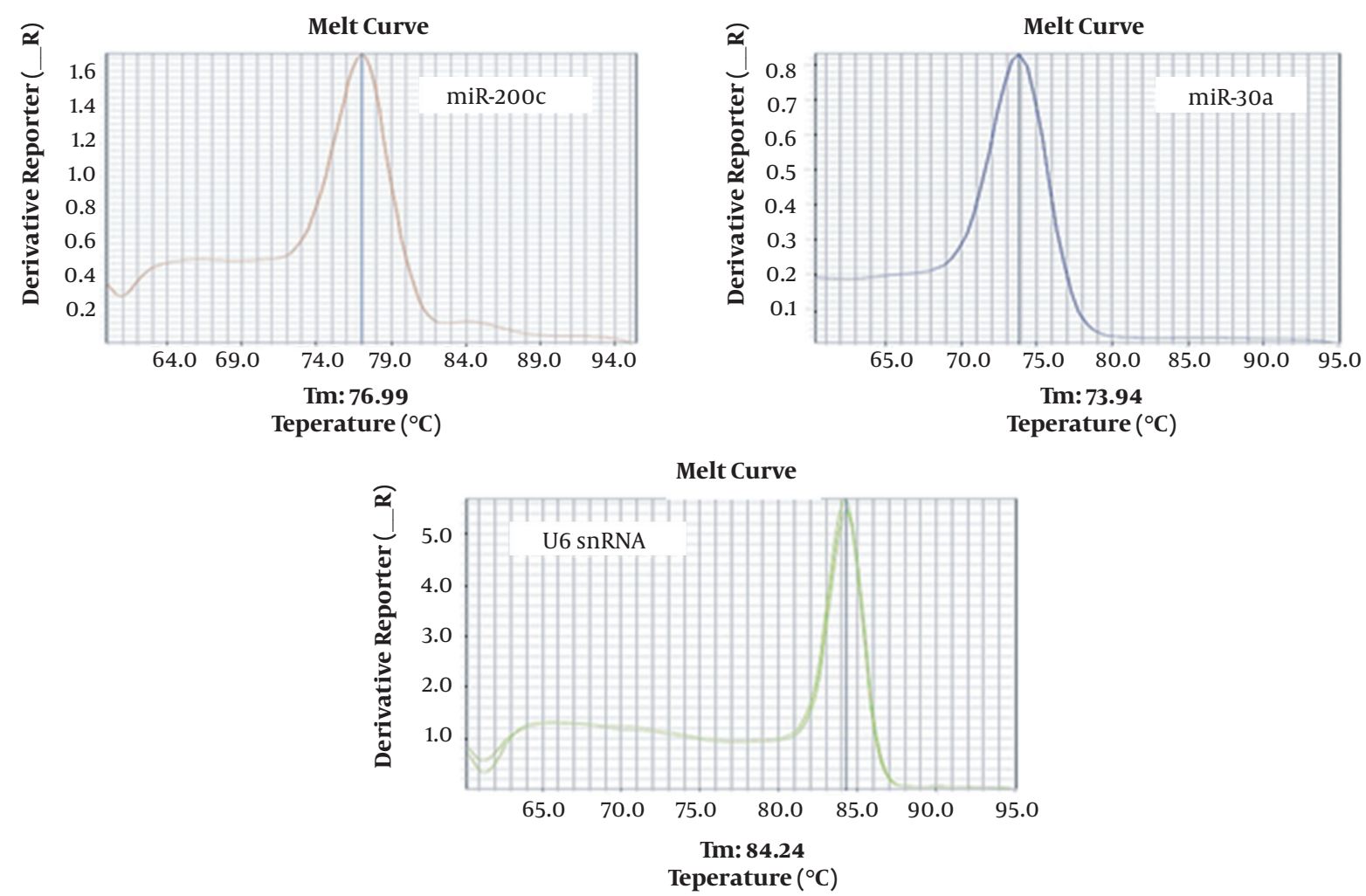

Figure 1. Specificity assessment of real-time PCR products through melting curve analysis for U6snRNA, miR-200c, and miR-30a genes. Each peak showed one of the PCR results with different melting temperatures.

In conclusion, we examined miR-30a and miR-200c expression levels and realized that miR-30a and miR-200c in stages III and IV had lower expression levels than stages I and II. The results of this study also showed that the expression levels of miR-30a and miR-200c were associated with tumor metastasis to lymphatic vessels in patients. In this regard, these two miRNAs showed decreased expression levels in patients with lymph node metastasis compared to patients with no lymph node metastasis, indicating a strong association between these biomarkers and BC. These results suggest that these biomarkers can be specifically used to screen for BC in different stages. In general, identifying the association between miRNA expression levels and clinical-pathological features of BC patients is important and may lead to the introduction of a diagnostic biomarker.

\section{Footnotes}

Authors' Contribution: HF conceived and supervised the study. NT and HF developed the theory and performed the experiments. All authors contributed to the analysis of the results and writing of the manuscript.

Conflict of Interests: The authors declare that there are no conflicts of interest.

Ethical Approval: The study was approved by the Ethics Committee of the Islamic Azad University, Tehran Branch.

Funding/Support: There is no funding.

Informed Consent: Patients completed the informed consent. 

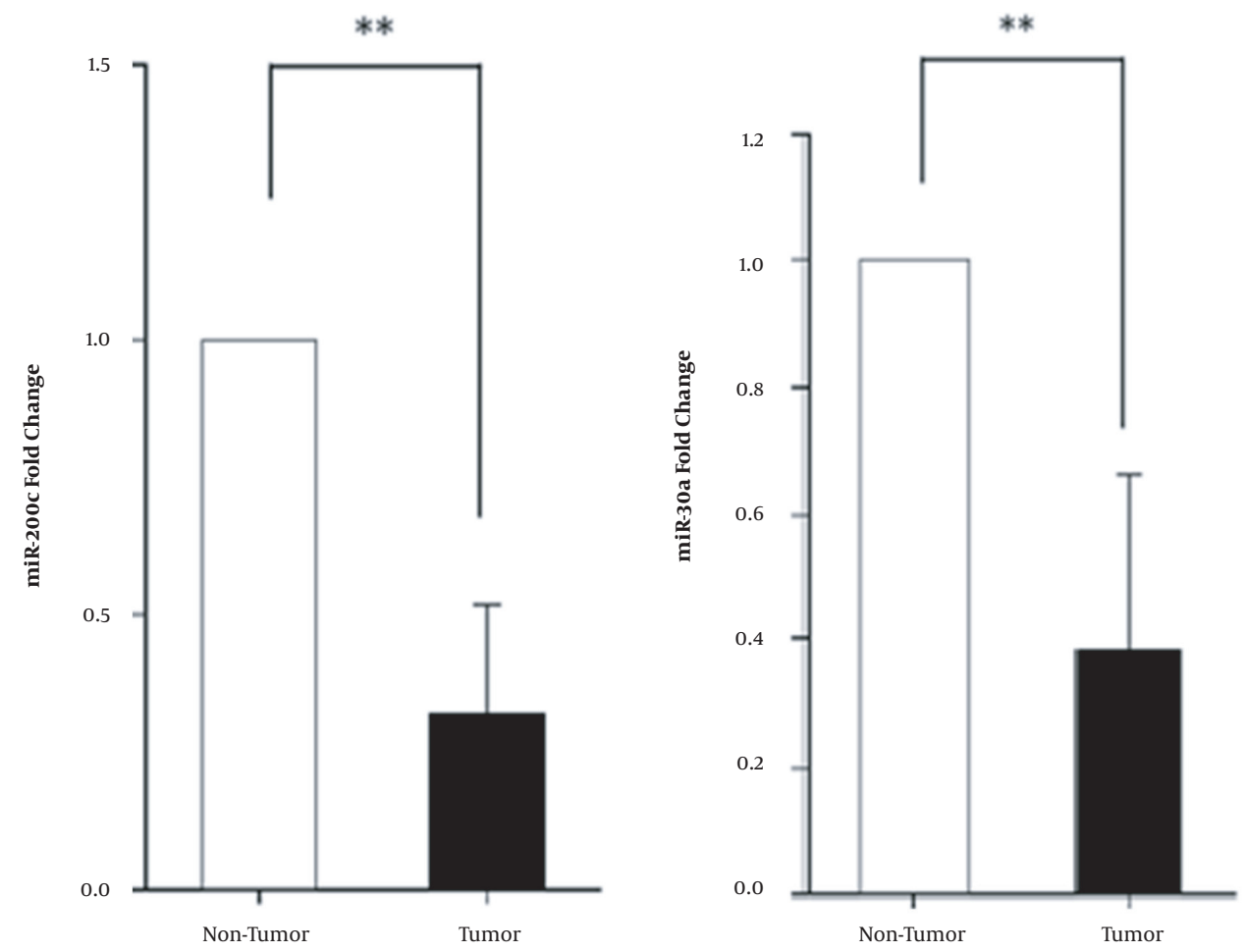

Figure 2. The miR-200c and miR-30a expression levels in breast tumor tissue compared to normal tissue surrounding the tumor. Data were normalized by U6 snRNA as a housekeeping gene.
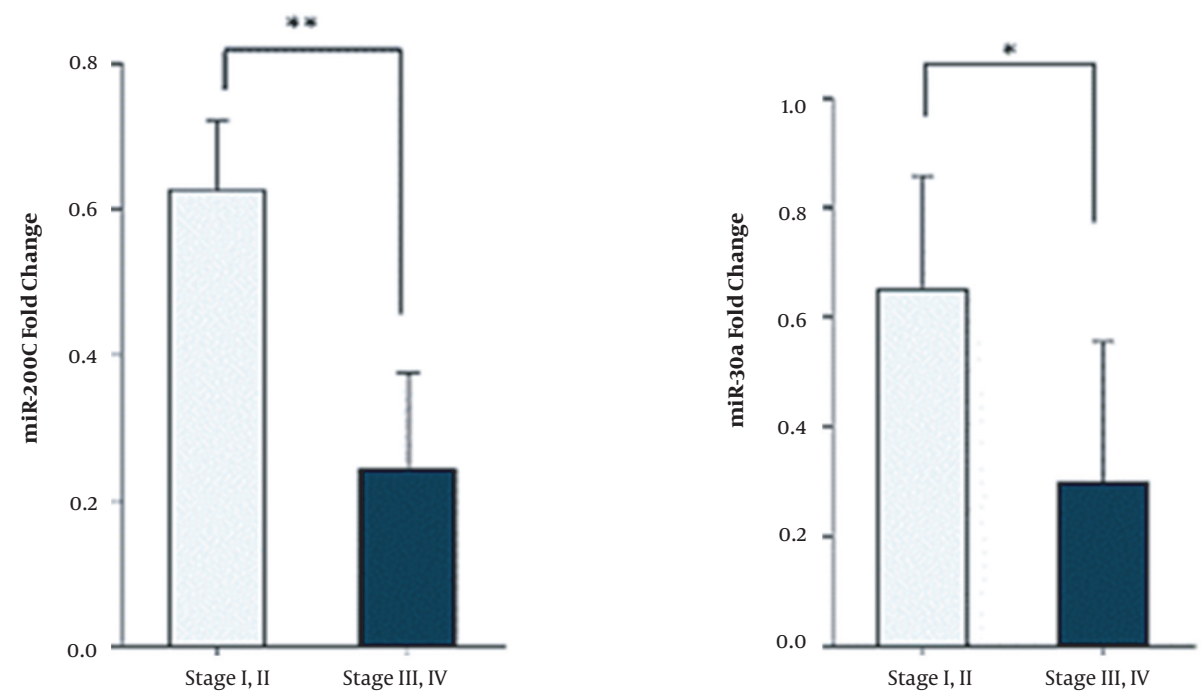

Figure 3. The miR-30a and miR-200c expression levels in tumor tissues in stages I and II compared to stages III and IV. 

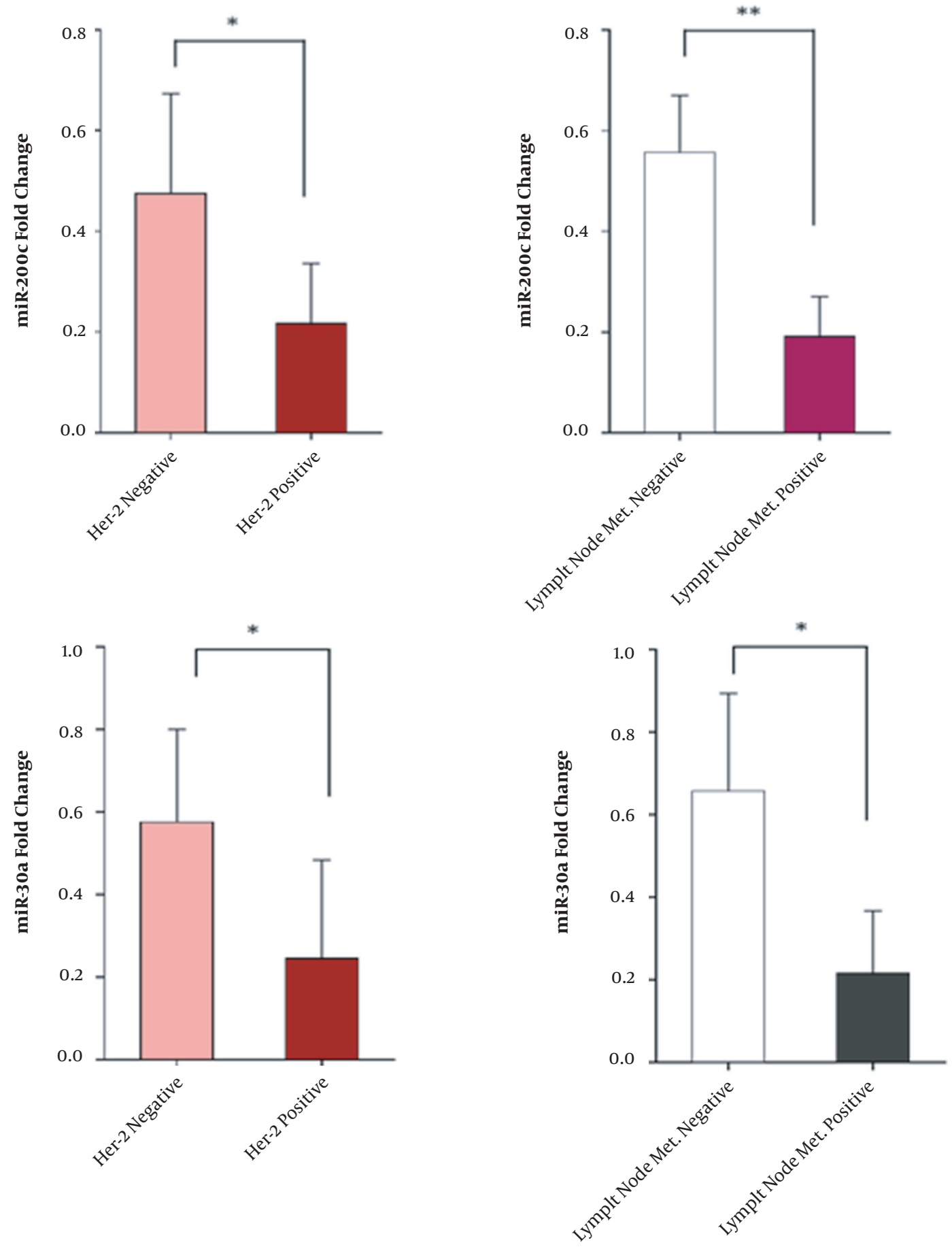


\section{ROC Curve: ROC of miR-200c}

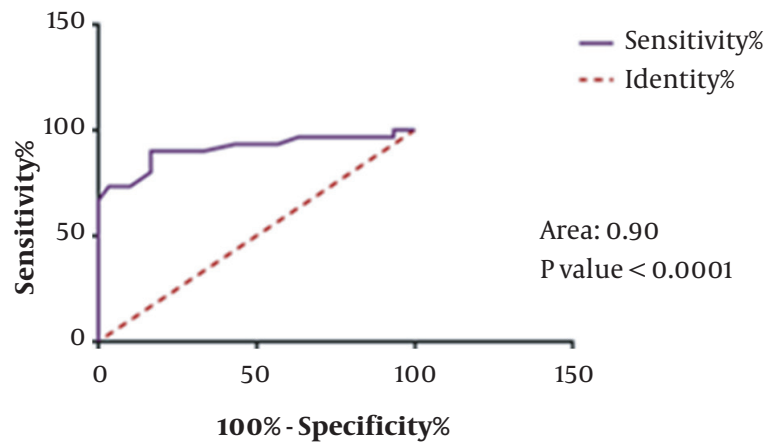

ROC Curve: ROC of miR-30a

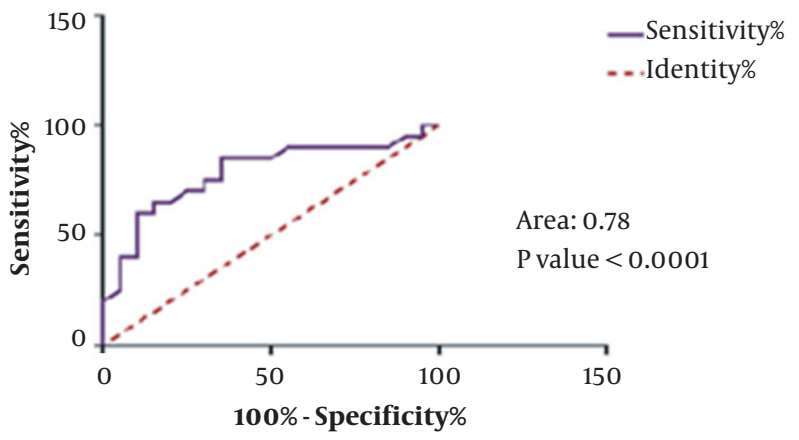

Figure 5. Analysis of the ROC curve for miR-200c and miR-30a.

\section{References}

1. Ferlay J, Soerjomataram I, Dikshit R, Eser S, Mathers C, Rebelo M, et al. Cancer incidence and mortality worldwide: sources, methods and major patterns in GLOBOCAN 2012. Int J Cancer. 2015;136(5):E359-86. doi: 10.1002/ijc.29210. [PubMed: 25220842].

2. Early Breast Cancer Trialists' Collaborative G. Effects of chemotherapy and hormonal therapy for early breast cancer on recurrence and 15-year survival: an overview of the randomised trials. Lancet. 2005;365(9472):1687-717. doi: 10.1016/S0140-6736(05)66544-0. [PubMed: 15894097].

3. Nguyen DX, Bos PD, Massague J. Metastasis: from dissemination to organ-specific colonization. Nat Rev Cancer. 2009;9(4):274-84. doi: 10.1038/nrc2622. [PubMed: 19308067].

4. Chen W, Hoffmann AD, Liu H, Liu X. Organotropism: new insights into molecular mechanisms of breast cancer metastasis. NPJ Precis Oncol. 2018;2(1):4. doi: 10.1038/s41698-018-0047-0. [PubMed: 29872722]. [PubMed Central: PMC5871901].

5. Heneghan HM, Miller N, Lowery AJ, Sweeney KJ, Newell J, Kerin MJ. Circulating microRNAs as novel minimally invasive biomarkers for breast cancer. Ann Surg. 2010;251(3):499-505. doi: 10.1097/SLA.ob013e3181cc939f. [PubMed: 20134314].

6. Prat A, Perou CM. Deconstructing the molecular portraits of breast cancer. Mol Oncol. 2011;5(1):5-23. doi: 10.1016/j.molonc.2010.11.003. [PubMed: 21147047]. [PubMed Central: PMC5528267].

7. McGuire A, Brown JA, Kerin MJ. Metastatic breast cancer: the potential of miRNA for diagnosis and treatment monitoring. Cancer Metastasis Rev. 2015;34(1):145-55. doi: 10.1007/s10555-015-9551-7. [PubMed: 25721950]. [PubMed Central: PMC4368851].

8. Yersal O, Barutca S. Biological subtypes of breast cancer: Prognostic and therapeutic implications. World J Clin Oncol. 2014;5(3):41224. doi: 10.5306/wjco.v5.i3.412. [PubMed: 25114856]. [PubMed Central: PMC4127612].

9. Slamon DJ, Clark GM, Wong SG, Levin WJ, Ullrich A, McGuire WL. Human breast cancer: correlation of relapse and survival with amplification of the HER-2/neu oncogene. Science. 1987;235(4785):177-82. doi: 10.1126/science.3798106. [PubMed: 3798106].

10. Slamon DJ, Godolphin W, Jones LA, Holt JA, Wong SG, Keith DE, et al. Studies of the HER-2/neu proto-oncogene in human breast and ovarian cancer. Science. 1989;244(4905):707-12. doi: 10.1126/science.2470152. [PubMed: 2470152].
11. Jemal A, Bray F, Center MM, Ferlay J, Ward E, Forman D. Global cancer statistics. CA CancerJClin.2011;61(2):69-90. doi:10.3322/caac.20107. [PubMed: 21296855].

12. Baek D, Villen J, Shin C, Camargo FD, Gygi SP, Bartel DP. The impact of microRNAs on protein output. Nature. 2008;455(7209):6471. doi: 10.1038/nature07242. [PubMed: 18668037]. [PubMed Central: PMC2745094].

13. Lim LP, Lau NC, Garrett-Engele P, Grimson A, Schelter JM, Castle J, et al. Microarray analysis shows that some microRNAs downregulate large numbers of target mRNAs. Nature. 2005;433(7027):769-73. doi: 10.1038/nature03315. [PubMed: 15685193].

14. Selbach M, Schwanhausser B, Thierfelder N, Fang Z, Khanin R, Rajewsky N. Widespread changes in protein synthesis induced by microRNAs. Nature. 2008;455(7209):58-63. doi: 10.1038/nature07228. [PubMed: 18668040].

15. Bushati N, Cohen SM. microRNA functions. Annu Rev Cell Dev Biol. 2007;23:175-205. doi: 10.1146/annurev.cellbio.23.090506.123406. [PubMed: 17506695].

16. Bartels CL, Tsongalis GJ. MicroRNAs: novel biomarkers for human cancer. Clin Chem. 2009;55(4):623-31. doi: 10.1373/clinchem.2008.112805. [PubMed: 19246618].

17. Cheng AM, Byrom MW, Shelton J, Ford LP. Antisense inhibition of human miRNAs and indications for an involvement of miRNA in cell growth and apoptosis. Nucleic Acids Res. 2005;33(4):12907. doi: 10.1093/nar/gki200. [PubMed: 15741182]. [PubMed Central: PMC552951].

18. Carthew RW, Sontheimer EJ. Origins and Mechanisms of miRNAs and siRNAs. Cell. 2009;136(4):642-55. doi: 10.1016/j.cell.2009.01.035. [PubMed: 19239886]. [PubMed Central: PMC2675692].

19. Davis BN, Hata A. Regulation of MicroRNA Biogenesis: A miRiad of mechanisms. Cell Commun Signal. 2009;7:18. doi:10.1186/1478-811X-7-18. [PubMed: 19664273]. [PubMed Central: PMC3224893].

20. Friedman RC, Farh KK, Burge CB, Bartel DP. Most mammalian mRNAs are conserved targets of microRNAs. Genome Res. 2009;19(1):92105. doi: 10.1101/gr.082701.108. [PubMed: 18955434]. [PubMed Central: PMC2612969].

21. Filipowicz W, Bhattacharyya SN, Sonenberg N. Mechanisms of posttranscriptional regulation by microRNAs: are the answers in sight? Nat Rev Genet. 2008;9(2):102-14. doi: 10.1038/nrg2290. [PubMed: 18197166]. 
22. Forman JJ, Legesse-Miller A, Coller HA. A search for conserved sequences in coding regions reveals that the let-7 microRNA targets Dicer within its coding sequence. Proc Natl Acad Sci U S A. 2008;105(39):14879-84. doi: 10.1073/pnas.0803230105. [PubMed: 18812516]. [PubMed Central: PMC2567461].

23. Hausser J, Landthaler M, Jaskiewicz L, Gaidatzis D, Zavolan M. Relative contribution of sequence and structure features to the mRNA binding of Argonaute/EIF2C-miRNA complexes and the degradation of miRNA targets. Genome Res. 2009;19(11):2009-20. doi: 10.1101/gr.091181.109. [PubMed: 19767416]. [PubMed Central: PMC2775596]

24. Hendrickson DG, Hogan DJ, McCullough HL, Myers JW, Herschlag D, Ferrell JE, et al. Concordant regulation of translation and mRNA abundance for hundreds of targets of a human microRNA. PLoS Biol.2009;7(11). e1000238. doi:10.1371/journal.pbio.1000238. [PubMed: 19901979]. [PubMed Central: PMC2766070].

25. Fang R, Zhu Y, Hu L, Khadka VS, Ai J, Zou H, et al. Plasma MicroRNA Pair Panels as Novel Biomarkers for Detection of Early Stage Breast Cancer. Front Physiol. 2018;9:1879. doi: 10.3389/fphys.2018.01879. [PubMed: 30670982]. [PubMed Central: PMC6331533].

26. Oztemur Islakoglu Y, Noyan S, Aydos A, Gur Dedeoglu B. MetamicroRNA Biomarker Signatures to Classify Breast Cancer Subtypes. OMICS. 2018;22(11):709-16. doi: 10.1089/omi.2018.0157. [PubMed: 30388053].

27. Zhang W, Liu J, Wang G. The role of microRNAs in human breast cancer progression. Tumour Biol. 2014;35(7):6235-44. doi: 10.1007/s13277014-2202-8. [PubMed: 24938874].

28. Cheng CW, Wang HW, Chang CW, Chu HW, Chen CY, Yu JC, et al. MicroRNA-30a inhibits cell migration and invasion by downregulating vimentin expression and is a potential prognostic marker in breast cancer. Breast Cancer Res Treat. 2012;134(3):1081-93. doi: 10.1007/s10549-012-2034-4. [PubMed: 22476851].

29. Chang CW, Yu JC, Hsieh YH, Yao CC, Chao JI, Chen PM, et al. MicroRNA30a increases tight junction protein expression to suppress the epithelial-mesenchymal transition and metastasis by targeting Slug in breast cancer. Oncotarget. 2016;7(13):16462-78. doi: 10.18632/oncotarget.7656. [PubMed: 26918943]. [PubMed Central: PMC4941328].

30. Kumarswamy R, Mudduluru G, Ceppi P, Muppala S, Kozlowski M, Niklinski J, et al. MicroRNA-30a inhibits epithelial-to-mesenchymal transition by targeting Snai1 and is downregulated in non-small cell lung cancer. Int J Cancer. 2012;130(9):2044-53. doi: 10.1002/ijc.26218. [PubMed: 21633953].

31. Fu J, Xu X, Kang L, Zhou L, Wang S, Lu J, et al. miR-30a suppresses breast cancer cell proliferation and migration by targeting Eya2. Biochem Biophys Res Commun. 2014;445(2):314-9. doi: 10.1016/j.bbrc.2014.01.174. [PubMed: 24508260].
32. Zhang N, Wang X, Huo Q, Sun M, Cai C, Liu Z, et al. MicroRNA30a suppresses breast tumor growth and metastasis by targeting metadherin. Oncogene. 2014;33(24):3119-28. doi: 10.1038/onc.2013.286. [PubMed: 23851509].

33. Li W, Liu C, Zhao C, Zhai L, Lv S. Downregulation of beta3 integrin by miR-30a-5p modulates cell adhesion and invasion by interrupting Erk/Ets1 network in triple-negative breast cancer. Int J Oncol. 2016;48(3):1155-64. doi:10.3892/ijo.2016.3319. [PubMed: 26781040].

34. Xiong J, Wei B, Ye Q, Liu W. MiR-30a-5p/UBE3C axis regulates breast cancer cell proliferation and migration. Biochem Biophys Res Commun. 2019;516(3):1013-8. doi: 10.1016/j.bbrc.2016.03.069. [PubMed: 27003255].

35. Zeng RC, Zhang W, Yan XQ, Ye ZQ, Chen ED, Huang DP, et al. Downregulation of miRNA-30a in human plasma is a novel marker for breast cancer. Med Oncol. 2013;30(1):477. doi: 10.1007/s12032-013-0477z. [PubMed: 23389917].

36. Kawaguchi T, Yan L, Qi Q, Peng X, Gabriel EM, Young J, et al. Overexpression of suppressive microRNAs, miR-30a and miR-200c are associated with improved survival of breast cancer patients. Sci Rep. 2017;7(1):15945. doi: 10.1038/s41598-017-16112-y. [PubMed: 29162923]. [PubMed Central: PMC5698306].

37. Hurteau GJ, Carlson JA, Spivack SD, Brock GJ. Overexpression of the microRNA hsa-miR-200c leads to reduced expression of transcription factor 8 and increased expression of E-cadherin. Cancer Res. 2007;67(17):7972-6. doi:10.1158/0008-5472.CAN-07-1058. [PubMed: 17804704].

38. Bai WD, Ye XM, Zhang MY, Zhu HY, Xi WJ, Huang X, et al. MiR-200c suppresses TGF-beta signaling and counteracts trastuzumab resistance and metastasis by targeting ZNF217 and ZEB1 in breast cancer. Int J Cancer. 2014;135(6):1356-68. doi: 10.1002/ijc.28782. [PubMed: 24615544].

39. Roy SS, Gonugunta VK, Bandyopadhyay A, Rao MK, Goodall GJ, Sun LZ, et al. Significance of PELP1/HDAC2/miR-200 regulatory network in EMT and metastasis of breast cancer. Oncogene. 2014;33(28):370716. doi: 10.1038/onc.2013.332. [PubMed: 23975430]. [PubMed Central: PMC3935988].

40. Marchini S, Cavalieri D, Fruscio R, Calura E, Garavaglia D, Fuso Nerini I, et al. Association between miR-200c and the survival of patients with stage I epithelial ovarian cancer: a retrospective study of two independent tumour tissue collections. Lancet Oncol. 2011;12(3):273-85. doi: 10.1016/S1470-2045(11)70012-2. [PubMed: 21345725].

41. Lu YX, Yuan L, Xue XL, Zhou M, Liu Y, Zhang C, et al. Regulation of colorectal carcinoma stemness, growth, and metastasis by an miR-200c-Sox2-negative feedback loop mechanism. Clin Cancer Res. 2014;20(10):2631-42. doi: 10.1158/1078-0432.CCR-13-2348. [PubMed: 24658157]. 